\title{
Electromagnetic Launcher Speed Control with a Multilevel Fast Triggering Time Algorithm (MFTTA)
}

\author{
Nail Tosun (D), Graduate Student Member, IEEE, Doğa Ceylan (D), Hakan Polat, Member, IEEE, \\ and Ozan Keysan (iD Member, IEEE, \\ Department of Electrical and Electronics Engineering \\ Middle East Technical University \\ Ankara, Turkey \\ nail.tosun@metu.edu.tr, polat.hakan@metu.edu.tr, doga.ceylan@metu.edu.tr, keysan@metu.edu.tr
}

\begin{abstract}
Electromagnetic launchers (EMLs) can provide accurate speed control of a projectile compared to gun-powder based alternatives. However large-caliber launchers have several pulse power supply (PPS) modules connected in parallel to reach the required current levels. Determination of the triggering instants of these parallel PPS modules is a crucial part of the launch mechanism. The triggering instants does not only affect the exit velocity but also the forces on the armature which can lead to transition i.e. separation of the armature from the rails. In this study, a triggering sequence optimization method that is faster than other alternatives in the literature and take into account speed-dependent parasitic masses and transition phenomena. Real-coded genetic algorithm (RCGA) and Partical Swarm Optimization (PSO) are used to create bencmarks. 32 capacitive PPS modules with $8 \mathrm{MJ}$ total energy is used. With the achieved accuracy and speed, this study offer: An effective speed control algorithm with several physical constraints.
\end{abstract}

Index Terms-Electromagnetic launchers (EMLs), Pulse Power Supplies (PPS), armature speed control.

\section{INTRODUCTION}

Electromagnetic launchers (EMLs) are electromechanical energy conversion machines that convert electrical energy to linear kinetic energy. The system consists of two parallel conducting rails, an armature and a non-conductive projectile and sabot petals that secure the projectile's correct positioning within the rails. The system is excited by pulse power supplies (PPS), which can supply currents in a few million-ampere range that creates a Lorentz force on the armature [1] $-[3]$. The force accelerates the launch package to a few thousand meters per second. Unlike explosive-based systems, EMLs inherently offer better velocity control for the projectile.

PPS's for EML applications are often capacitor-based topologies [4]. In order to produce a few MJ electrical energy, several capacitor-based PPS modules should be connected in parallel. Since there are many units in the PPS, each unit's triggering time affects the total discharge current waveform

(C) 2020 IEEE. Personal use of this material is permitted. Permission from IEEE must be obtained for all other uses, in any current or future media, including reprinting/republishing this material for advertising or promotional purposes, creating new collective works, for resale or redistribution to servers or lists, or reuse of any copyrighted component of this work in other works.

Corresponding author: Ozan Keysan e-mail: keysan@metu.edu.tr
[5]. Thus, timing sequence PPS should be optimized in order to enhance the performance of the EML. Optimization of the PPS unit's timing sequence though different objectives and constraints is a well-studied problem in the literature. However, most of them use evolutionary algorithms such as genetic algorithm (GA) and Particle Swarm Optimization (PSO). These algorithms are useful to find local minima even though there are multiple input features and non-linear behaviors between objectives and features. However, the cost is the excessive number of function evaluations.

The usage of GA for triggering time optimization problem (TTOP) has the following motivation: the relation between the desired rail current waveform and the set of triggering times is nonprogrammable or requires hardware modifications to control the output waveform shape [6]. The triggering time's nonprogrammable nature results in large numbers of input parameters, i.e., each triggering time becomes a parameter. Thus, GA has better performance on large dimensional input space so that it is a convenient way to use in TTOP [5]-[9]. However, the relation between rail current waveform and the set of triggering times in fact can be programmable in specific rail current shapes. For example, Zhang et al. [10] states that for a given magnitude of flat rail current, the set of triggering time that ensures the desired rail current is unique and can be calculated iteratively. The proposed iterative algorithm is compared with GA-based solutions of TTOP, and the iterationbased method has preferable effects on calculating timing sequence [11].

In this study, we proposed an iterative algorithm that calculates the set of triggering time for given muzzle velocity. The flat-top rail current waveform is targeted; however, it did not be considered a constraint to the optimization algorithm. The flatness of the rail current is obtained by an internal control algorithm, which reduced the optimization problem's complexity. Apart from other iterative-based solutions of TTOP in literature [10], [11], our model has an additional constraint on down-slope rail current, which reduces transition risks. Moreover, the study conducted with different capacitor voltage so that the vertex of the TTOP under given constraint is explained. The algorithm is compared with non-iterative algorithms in the literature, GA and PSO. These algorithms 
TABLE I

EML DESIGN PARAMETERS AND LiMitaTions.

\begin{tabular}{lc}
\hline Rail Height & $70 \mathrm{~mm}$ \\
Rail Separation & $70 \mathrm{~mm}$ \\
Rail Width & $50 \mathrm{~mm}$ \\
Rail Length & $5 \mathrm{~m}$ \\
Pre-load Distance & $70 \mathrm{~cm}$ \\
Projectile Mass & $500 \mathrm{~g}$ \\
Maximum Linear Current Density & $32.5 \mathrm{kA} / \mathrm{mm}$ \\
Maximum Peak Current & $2275 \mathrm{kA}$ \\
\hline
\end{tabular}

are used to create benchmarks to show the computational load deficit when the proposed algorithm is used. For clarity, the EML design and limitations are used, which are listed in Table 1.

The organization of the paper is the following: In Section II, the literature survey of the TTOP is provided, and the main objectives and constraints of these problems are revealed. Then, the simulation model used in this study is explained in Section III. The proposed model is described and compared with the GA and PSO models in Section IV. Finally, the conclusions are exhibited in Section V.

\section{LiterATURE SURVEY OF TTOP}

Triggering strategy is one of the critical features that affect EML efficiency, and the systems' generated forces. Thus, TTOP is a well-studied topic in the literature. These studies can be divided into two parts in terms of their objectives. These are listed in the following subsections. Studies can be found in the Table 2 .

TABLE II

Literature Survey on Triggering Time Algorithms.

\begin{tabular}{|c|c|}
\hline & Objective \\
\hline [10] & Muzzle velocity \\
\hline$[?]$ & Muzzle velocity \\
\hline 8 & Max velocity, $\max$ efficiency \\
\hline 9 & Max velocity, max efficiency \\
\hline 5 & Desired current waveform \\
\hline [12] & Muzzle velocity \\
\hline
\end{tabular}

$\begin{array}{ll}\text { Method } & \text { Constaints } \\ \text { Iterative } & - \\ \text { GA } & \text { Current } \\ \text { GA, NSGA-II } & \text { Accelaration } \\ \text { GA, NSGA-II } & \text { Current } \\ \text { GA } & \\ \text { Harmony Search, ODM } & \text { Current }\end{array}$

\section{A. Optimizing the Triggering Times to Obtain the Maximum Muzzle Velocity}

EML efficiency depends on the triggering strategy. Although the $\mathrm{L}^{\prime}$, one of the important parameter which determines the EML efficiency, is not dependent the triggering strategy, other parameters such as linear current density $\tilde{\mathrm{J}}_{\text {linear }}$, the muzzle current, $\mathrm{I}_{\text {exit }}$ have an influence on the launch mechanism. An example of such TTOP is given in (1). The objective of the problem is maximizing the muzzle/exit velocity denoted as $\mathrm{v}_{\text {exit }}$. Constraints are adjusted considering the transition phenomena, which is linked heavily to the launch security. The transition phenomenon is described as the transition of solid contact into arcing contact. Multiple mechanisms cause transition [13]. One of them is the $\tilde{\mathrm{J}}_{\text {linear. }} \mathrm{I}_{\max }$ refers to the maximum allowed rail current, which is related to rail dimension and the $\tilde{J}_{\text {linear }}$. Therefore, for a pre-defined EML geometry and selected $\tilde{\mathrm{J}}_{\text {linear }}, \mathrm{I}_{\max }$ can be introduced as a constraint to the magnitude of the pulse shape current denoted as $\mathrm{I}_{\text {ref }}$. $\mathrm{I}_{\text {exit }}$ is considered as another transition constraint. $\mathrm{I}_{\text {exit }}$ is responsible for the so-called "down-slope transition", which is reported by different studies in the literature. Wang et al. [14] reported that the down-slope transition occurs when the

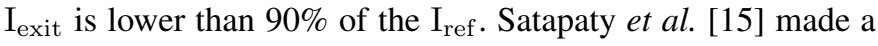
statistical analysis based on the experiments and showed that the down-slope transition occurs when $\mathrm{I}_{\text {exit }}$ is lower than $80 \%$ of the $\mathrm{I}_{\text {ref }}$. It should be noted that these studies were conducted with small and medium caliber EMLs, respectively.

$$
\begin{array}{ll}
\max & \mathrm{v}_{\text {exit }} \\
\text { subject to } & \mathrm{I}_{\text {ref }} \leq \mathrm{I}_{\text {max }} \\
& \mathrm{I}_{\text {exit }} \geq 0.5 \mathrm{I}_{\text {ref }} \\
& \left|\mathrm{I}_{\text {rail }}-\mathrm{I}_{\text {ref }}\right|_{\text {RMS }} \leq \epsilon \mathrm{I}_{\text {ref }} \quad t \in\left[t_{1}, t_{2}\right]
\end{array}
$$

The third constraint is the deviation of the pulse current wave-shape. RMSE is used as an error measure, which is defined in (2). n represents the number of current samples. $\epsilon$ in the third constraint in the (1) is the allowed deviation in the $\mathrm{I}_{\text {rail. }}$ It should be in the form of a flat-top pulse shape. Sharp variations in the rail currents are undesirable due to voltage oscillations in the EML, which is considered as inductive load.

$$
\mathrm{RMSE}=\sqrt{\frac{1}{\mathrm{n}} \sum_{\mathrm{i}=1}^{\mathrm{n}}\left(\mathrm{I}_{\text {ref }}-\mathrm{I}_{\text {rail }}\right)^{2}}
$$

Zhengjun et al. [8] made a TTOP study that maximize $\mathrm{V}_{\text {exit }}$ and efficiency. Since two objectives are targeted, the Pareto frontier is used. The acceleration of the armature is constrained. The deviation of the pulse current shape, as well as $\mathrm{I}_{\text {exit }}$ is not considered. Yu et al. made another TTOP study that has the same objective as [8]. $\mathrm{I}_{\text {ref }}$ is constrained, considering the maximum allowed acceleration. The novelty of the simulation model, the addition of VSE and contact resistances, are introduced. However, $\mathrm{I}_{\text {exit }}$ and the quality of the pulse current waveform is not recognized. Moreover, both studies used an evolutionary algorithm that is computationally expensive.

\section{B. Optimizing the Triggering Times to Ensure Desired Muzzle Velocity}

Efficiency can be sacrificed when the tactical operation is deemed in EMLs. Therefore, TTOP should have different objectives rather than maximizing $v_{\text {exit. }}$. An example of such TTOP is represented in (3). The objective of the TTOP is the diminishing the quadratic velocity error. $l_{1}$ norm/absolute error is not considered as a minimizer considering its nondifferentiable nature. (3) shares the same constraints with (1).

$$
\begin{array}{ll}
\min & \left(\mathrm{v}_{\text {desired }}-\mathrm{v}_{\text {exit }}\right)^{2} \\
\text { subject to } & \mathrm{I}_{\text {ref }} \leq \mathrm{I}_{\max } \\
& \mathrm{I}_{\text {exit }} \geq 0.5 \mathrm{I}_{\text {ref }} \\
& \left|\mathrm{I}_{\text {rail }}-\mathrm{I}_{\text {ref }}\right|_{\text {RMS }} \leq \epsilon \mathrm{I}_{\text {ref }} \quad t \in\left[t_{1}, t_{2}\right]
\end{array}
$$

Chao et al. [12] used a harmony search algorithm for TTOP. Desired muzzle velocity $\mathrm{v}_{\text {desired }}$ is targeted. $\mathrm{I}_{\max }$ is used as an 
constraint. However, $\mathrm{I}_{\text {exit }}$ is not considered. Zhang et al. [10] used an iterative algorithm rather than evolutionary algorithms for the TTOP. $v_{\text {desired }}$ is targeted. The shape of the pulse rail current is constrainted. However, the efficiency is not considered. Liu et. al maximized the efficiency with $\mathrm{v}_{\text {defined }}$ under the $\mathrm{I}_{\max }$ constraint. However, $\mathrm{I}_{\text {rail }}$ does not consider the pulse waveform as well as the $\mathrm{I}_{\text {exit }}$ constraint.

\section{The Simulation Model}

The detailed analysis of EMLs requires 3-D Finite Element Method (FEM) simulations. However, optimizations with 3D FEM are time-consuming; thus, appropriate simplifications should be made to have reasonable computation time [16]. In this section, these simplifications and the construction of the 1-D EML model is explained. The EML can be modeled with an R-C circuit. The R-C circuit is illustrated in Fig. 1. $\mathrm{R}_{\mathrm{EML}}$ and $\mathrm{L}_{\mathrm{EML}}$ represent the total resistance and inductance of the EML, respectively. It should be noted that $R_{\mathrm{EML}}$ is dependent not only position but also frequency $(f)$ and the armature velocity $(v)$.

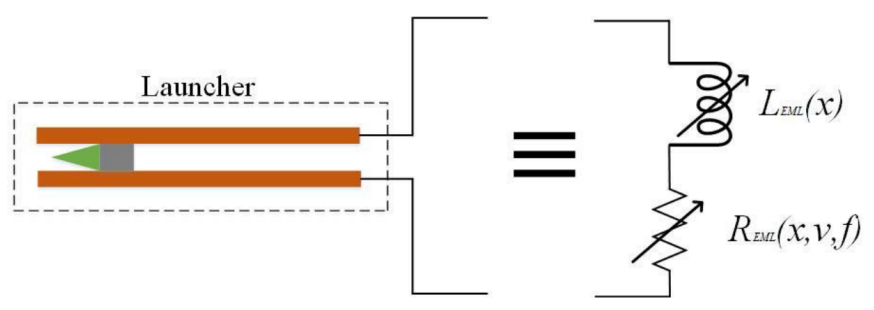

Fig. 1. The R-L approximation of the EML system. $\mathrm{L}_{\mathrm{EML}}$ and $\mathrm{R}_{\mathrm{EML}}$ defined as equivalent inductance and resistance of electromagnetic launcher.

In EMLs, there are mainly three major elements affecting the $R_{E M L}$ like in (4). The AC resistance, $R_{a c}$ occurs when there is a change in the rail excitation current due to skin and proximity effects. The second element is the velocity skin effect resistance $\left(R_{v s e}\right)$, which happens at the trailing edge of the armature-rail contact interface and is highly dominant at high projectile velocities. The last element is the back-emf at the breach denoted as $\mathcal{E}$, which can be modeled as a resistor. $\left(\mathrm{R}_{\mathrm{emf}}\right)$. Although back-emf is not a resistive component from a physical perspective, it can be modeled with a resistor from a mathematical perspective like in $(5,6)$.

$$
\begin{aligned}
& R_{\mathrm{EML}}=\mathrm{R}_{\mathrm{vse}}(\mathrm{v})+\mathrm{R}_{\mathrm{ac}}(\mathrm{f})+\mathrm{R}_{\mathrm{emf}}(\mathrm{v}) \\
& \mathcal{E}=\frac{\mathrm{dL}(\mathrm{t})}{\mathrm{dt}} \mathrm{I}(\mathrm{t})+\mathrm{L}(\mathrm{t}) \frac{\mathrm{dI}(\mathrm{t})}{\mathrm{dt}} \\
& \mathcal{E}=\mathrm{R}_{\mathrm{emf}} \mathrm{I}(\mathrm{t})+\mathrm{L}(\mathrm{t}) \frac{\mathrm{dI}(\mathrm{t})}{\mathrm{dt}}
\end{aligned}
$$

As stated in [16] and [17] the $\mathrm{L}_{\mathrm{EML}}$ has two components. $\mathrm{L}_{\text {ext }}$ is the inductance between the rails and $L_{i n t}$ is the inductance component inside the rails. In (7) calculation of the total inductance gradient $\left(\mathrm{L}^{\prime}\right)$ was presented. $\mathrm{B}$ equals to $\mathrm{B}_{\mathrm{z}}$ due to symmetry. Multiplied with the number of turns (single turn in our case), the surface integral of $B_{z}$ results in flux linkage $\lambda$. When $\lambda$ is divided by the rail current results in the instantaneous inductance of the rails is obtained. In order to find the total transient inductance gradient, flux linkage $\lambda$ was divided to $\mathrm{I}_{\text {rail }}$, and the distance between the breech and the $\mathrm{B}=0$ contour line inside of the armature which is denoted by $\mathrm{x}_{0}$. The $\mathrm{L}_{\mathrm{EML}}$ calculation was given in (8). The integration area and $\mathrm{x}_{0}$ can be seen in Fig. 2

$$
\begin{aligned}
& \mathrm{L}_{\text {ext }}^{\prime}+\mathrm{L}_{\text {int }}^{\prime}=\frac{\frac{1}{2 \mathrm{I}_{\text {rail }}} \int\left|\mathrm{B}_{\mathrm{z}}\right| \mathrm{dA}}{\mathrm{x}_{0}} \\
& \mathrm{~L}_{\mathrm{EML}}(\mathrm{x})=\left(\mathrm{L}_{\text {ext }}^{\prime}+\mathrm{L}_{\text {int }}^{\prime}\right) \mathrm{x}
\end{aligned}
$$

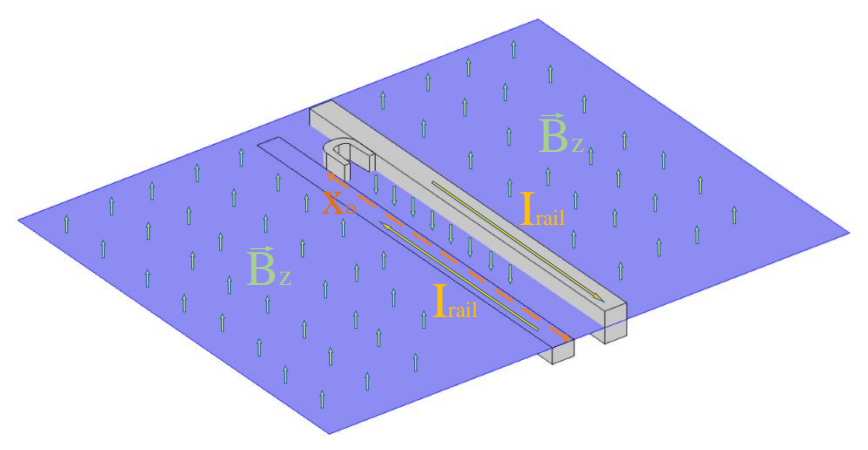

Fig. 2. Integration boundary and $\mathrm{x}_{\mathrm{O}}$.

$\mathrm{R}_{\mathrm{ac}}^{\prime}$, $\mathrm{L}_{\text {ext }}^{\prime}$ and $\mathrm{L}_{\mathrm{int}}^{\prime}$ is found by calculating gradients while keeping the armature stationary in 3-D FEM. These gradients are used to create position-dependent lumped parameters updated with the armature motion in the 1-D model. $R_{v s e}$ was found by 2-D moving armature simulations. In the VSE calculation study, a DC was applied, and the simulation was repeated for different constant armature velocities. The total resistance of the rail is calculated using the ohmic loss calculation as in (10). However, DC resistance, as stated in (9), used to isolate $R_{v s e}$ as in (11). Hence an empiric formulation was developed and used during the simulation. In (9-11), the resistivity of the rails is denoted as $\rho_{\text {rail }} . J_{\text {rail }}$ and $\|$. represents the current density inside the rails and $l_{2}$ norm, respectively.

$$
\begin{aligned}
& \mathrm{R}_{\text {rail }}(\mathrm{x})=\rho_{\text {rail }} \mathrm{xA} \\
& \mathrm{R}_{\mathrm{ac}}(\mathrm{x})=\mathrm{x} \frac{1}{\mathrm{I}(\mathrm{t})^{2}} \iiint_{\mathrm{V}} \rho_{\text {rail }}\left\|\mathrm{J}_{\text {rail }(\mathrm{t})}\right\|^{2} \mathrm{dV} \\
& \mathrm{R}_{\mathrm{vse}}(\mathrm{v})=\frac{1}{\mathrm{I}(\mathrm{t})^{2}} \iiint_{\mathrm{V}} \rho_{\text {rail }}\left\|\mathrm{J}_{\text {rail }(\mathrm{t})}\right\|^{2} \mathrm{dV}-\rho_{\text {rail }} \mathrm{xA}
\end{aligned}
$$

Due to the lack of a 3D body in the 1-D simulation environment, transients of $L^{\prime}$ and $R_{a c}$ is not achievable. In [16], $R_{a c}$ is relatively high during the early stages of the 
launch compared to $\mathrm{R}_{\mathrm{vse}}$ and $\mathrm{R}_{\mathrm{emf}}, \mathrm{R}_{\mathrm{vse}}$ and $\mathrm{R}_{\mathrm{emf}}$ are the dominating resistances after $500 \mathrm{~m} / \mathrm{s}$. Moreover, in our study, the flat-top current further reduces the skin effect; hence $\mathrm{R}_{\mathrm{ac}}$ was neglected during the analysis. In this study, special attention to $\mathrm{L}^{\prime}$ calculation is given due to precise transient modeling. A 3D FEM model is performed to investigate the following theorem, which is similar to the study in [16] and [17].

Theorem 3.1: Total inductance gradient $\left(\mathrm{L}_{\text {ext }}^{\prime}+\mathrm{L}_{\text {int }}^{\prime}\right)$ is invariant from $\mathrm{I}_{\mathrm{ref}}$ when pulse rail current is applied. The rise time of the rail currents kept constant, considering the rail currents form from identical PPS units.

The variation of $\mathrm{L}^{\prime}$ with different rail current pulses needs to be analyzed. In Fig. 3 the rail geometry and in Fig. 4 the excitation currents are presented. According to Fig. 4 the total inductance gradient does not change for different pulse current excitations. In this figure, non-optimized $I_{\text {rail }}$ is showed for better understanding of the third constraint of (1) and (3).

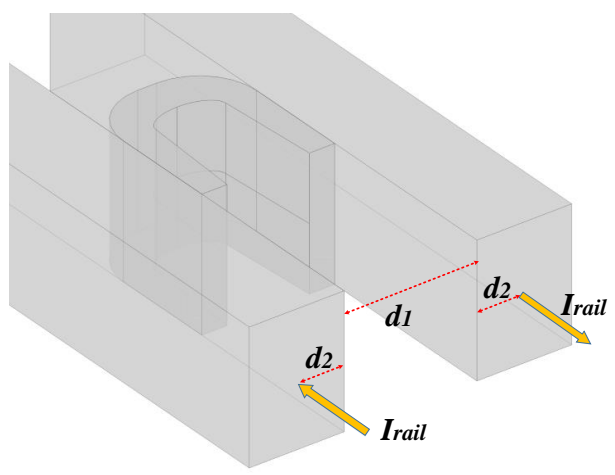

Fig. 3. Concentrated coil approach, breech to muzzle cross-section.

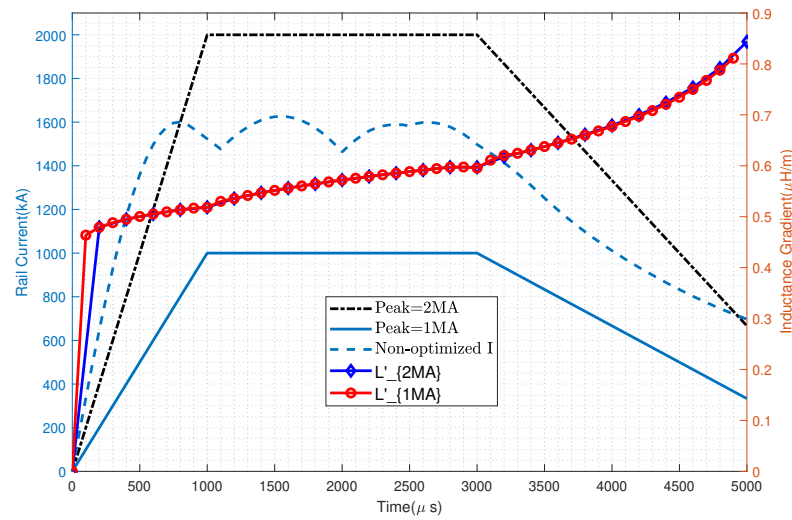

Fig. 4. Current excitation on the rails, resultant transient inductance gradients and non-optimized current waveform.

It is possible to consider the rails as a single turn concentrated coil where the effective distance between the rails changes due to the dependence of skin effect on the change in the rail excitation current. In Fig. 3 the distance between the rails geometry is $d_{1}$, the distances between the concentrated current and inner edge of the rails are $\mathrm{d}_{2}$ and therefore the effective distance between the rails is $\mathrm{d}_{\text {coils }}=\mathrm{d}_{1}+2 \mathrm{~d}_{2}$.

If there is a change in the magnitude of current (i.e $\frac{\mathrm{dI}}{\mathrm{dt}}$ ), $\mathrm{d}_{\text {coils }}$ gets closer to $\mathrm{d}_{1}$ since due to skin effect current concentrates on the inner surface of the rails (as in current rise at the first few ms.). However, as the current reaches to flat top of the waveform, the current distribution gets more homogeneous, and hence more flux-linkage $(\lambda)$ is obtained. Moreover, since the change in total $\mathrm{L}^{\prime}$ is independent of current pulse shape, the same $\mathrm{L}^{\prime}$ can be used during 1-D modeling. Thus, there is no need for 3-D FEM simulation for accuracy of $\mathrm{L}^{\prime}$, when the triggering times are optimized.

\section{Multi-Level FAst Triggering Time Algorithm}

Multiple capacitive PPS modules are used to achieve higher energized projectile in EML applications. Parallelling is applied to complete this task. An example of such a system is demonstrated with Fig. 5. 16 PPS modules are used. For larger-caliber as well as higher energy EMLs, the number of capacitive PPS unit is also increased. In this study, 32 capacitive PPS module is used for that purpose. Since there are multiple electrical excitation modules, there is $\mathrm{N}$ triggering time, which should be optimized. The design variables showed as following vector notation where i represent PPS module index and $\alpha$ represents the number of initial firing;

$$
\begin{aligned}
& \vec{t}=\left(\begin{array}{c}
t_{\alpha} \\
\vdots \\
\vdots \\
\vdots \\
\vdots \\
t_{32}
\end{array}\right) \quad 0 \leq t_{i} \leq 4 \mathrm{~ms} \quad \forall i \in[\alpha, 32] \\
& \mathrm{t}_{\mathrm{i}}=0 \quad \forall i \in[1, \alpha]
\end{aligned}
$$

MFTTA consists of two main parts. The first part is a hysteresis control of $I_{\text {rail }}$ with the $I_{\text {ref }}$, which is the peak of the trapezoidal current waveform. Then, the algorithm determines how many modules to be fired at the beginning. The pulse current shape is conserved with a hysteresis control in the simulation model. The hysteresis control is made with COMSOL's Event interface, where the simulation can be stopped with predefined variable conditions. Therefore, when $I_{\text {rail }}$ is below $I_{\text {ref }}$, the event interface is triggered and saves the time where this event happened. This time can be used as a new triggering time, since the new triggering can hold the $I_{\text {rail }}$ at the $I_{\text {ref }}$ level, thanks to the additional energy comes from the new PPS module. The second part of the MFTTA is responsible for the find the $I_{\text {ref }}$ that ensures the $v_{\text {desired }}$. Each part is explained in the following subsections. The pseudocode of the algorithm is given in Algorithm 1. 


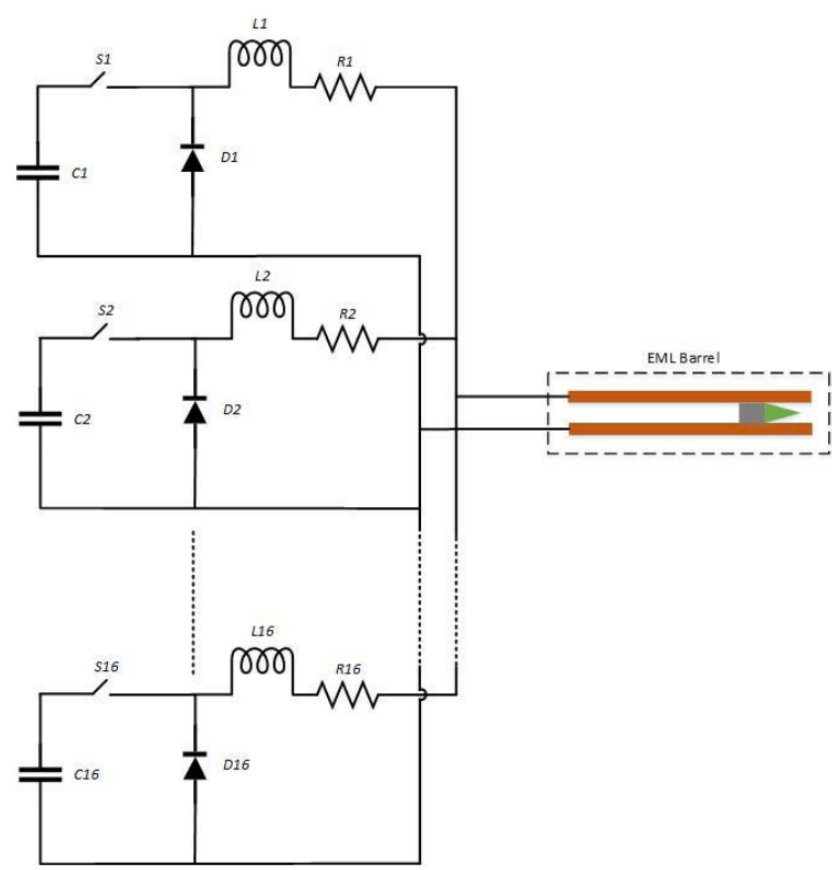

Fig. 5. The connection of pulse power supplies to EML. In this study 32 capacitive based PPS module connected parallel to EML

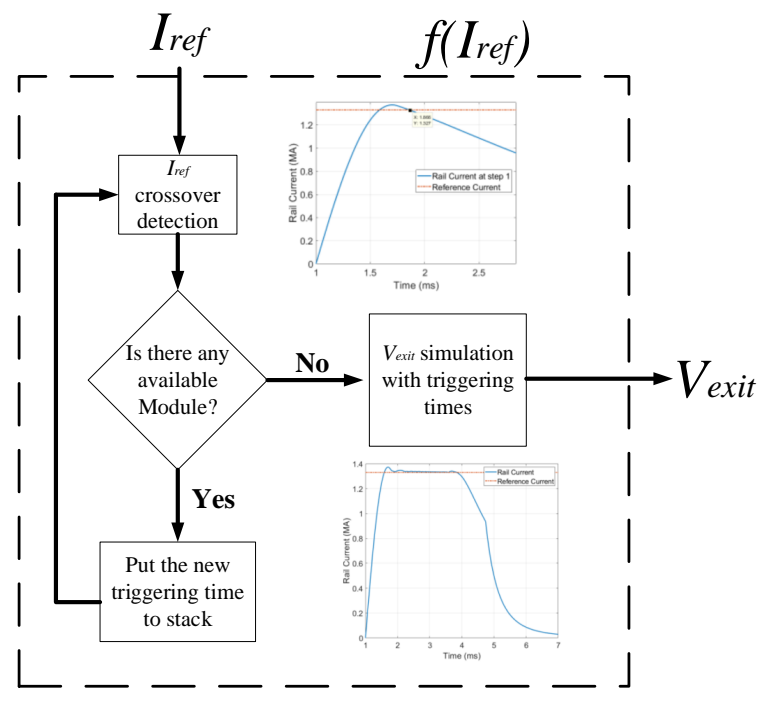

Fig. 6. PCSHC. The algorithm takes input as $\mathrm{I}_{\text {ref }}$ and give $\mathrm{N}$ amount triggering time which associated with a unique $\nu_{\text {exit }}$. The algorithm spend $\mathrm{N}-\mathrm{M}$ circuit simulation time for all obtaining triggering times.

\section{A. Pulse Current Shape with Hysteresis Control(PCSHC)}

The flowchart of the PCSHC is illustrated in Fig. 6. The first part is a hysteresis control of rail current with the given reference current $I_{\text {ref }}$ which is the peak of the trapezoidal current waveform. Intermediate results of the hysteresis control is illustrated in Fig. 7. Then, the algorithm determines how many modules to be fired at the beginning. The rail current waveforms with various initial firing sequences are given in Fig. 8. The maximum current limit is determined by the maximum linear current density constraint. After selecting the

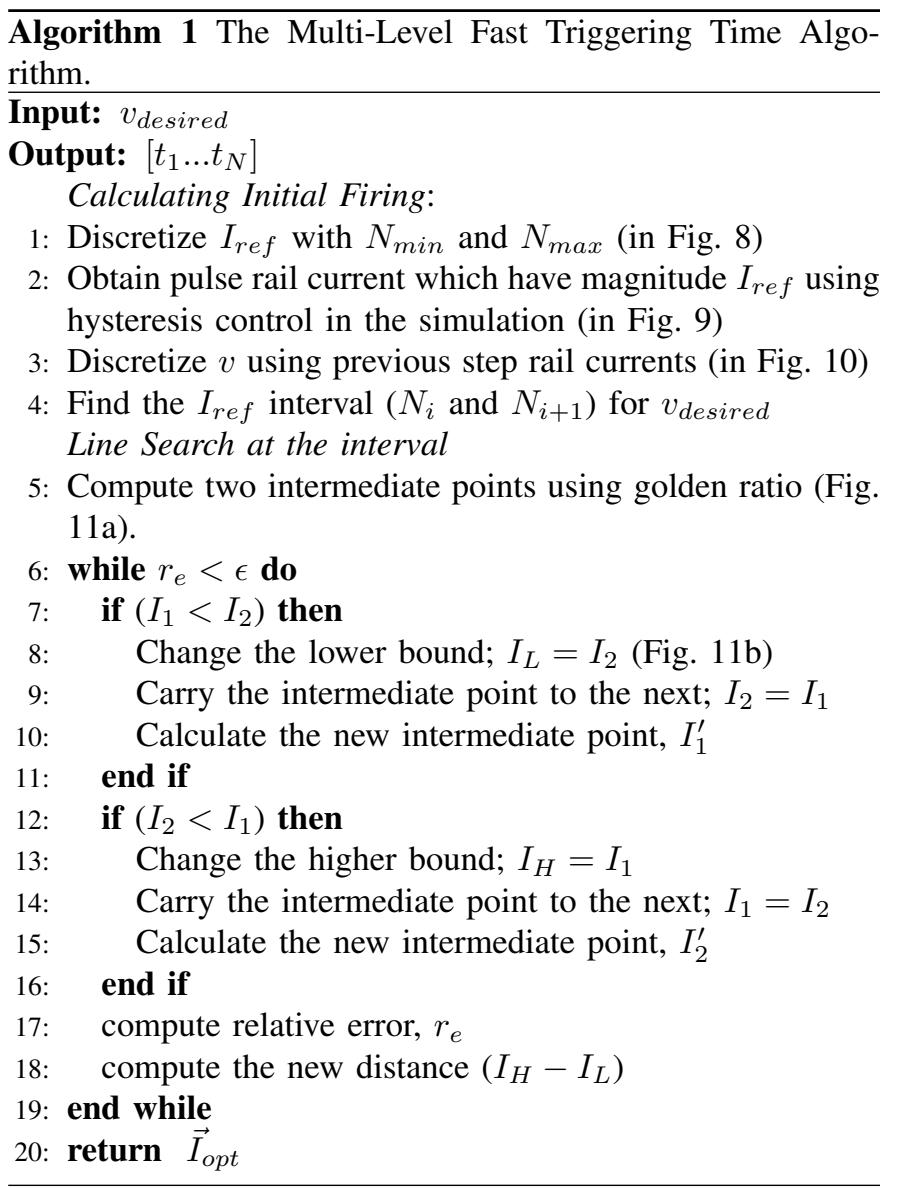

number of initial firing modules, the algorithm tries to find the next triggering points which create pulse shaped rail current at $\mathrm{I}_{\text {ref. }}$. COMSOL's Event interface is used to build an hysteresis control. Simulation is aborted just after the new trigger point is generated to reduce the computation time. The results of the first part of the algorithm with respect to various $I_{\text {ref }}$ values are given in Fig. 9 If the pulse power supply unit has $\mathrm{N}$ parallel modules and one simulation takes $\mathrm{T}$ time, after selecting the initially fired modules ( denoted as $\mathrm{M}$ ), firing instants of $\mathrm{N}-\mathrm{M}$ units need to be determined. This means that the simulation has to be repeated $\mathrm{N}-\mathrm{M}$ times for pulse current waveform which has a magnitude of $\mathrm{I}_{\text {ref }}$. Since there is a stop condition in simulations, simulations are aborted immediately after finding the triggering instant, controller finds triggering sequence at $(\mathrm{N}-\mathrm{M}) \mathrm{t} / 2$ time, neglecting the convergence time of the simulation. Simulations take a few seconds since the study conducted in 1-D.

\section{B. Determination of the Required $\mathrm{I}_{\mathrm{ref}}$ for Desired Exit Velocity}

The first part of the algorithm generates triggering sequence with given current limit $I_{\text {ref }}$. However, at this stage the $I_{\text {ref }}$ for a unique projectile muzzle velocity is still unknown. For this purpose following theorem is proposed by [10].

Theorem 4.1: There exist a unique $\mathrm{I}_{\mathrm{ref}}$ for given exit velocity. Therefore, there exits a unique set of triggering times for every exit velocity value.

Such a statement is true with the assumption of constant capacitor voltage and constant launch package mass. The 

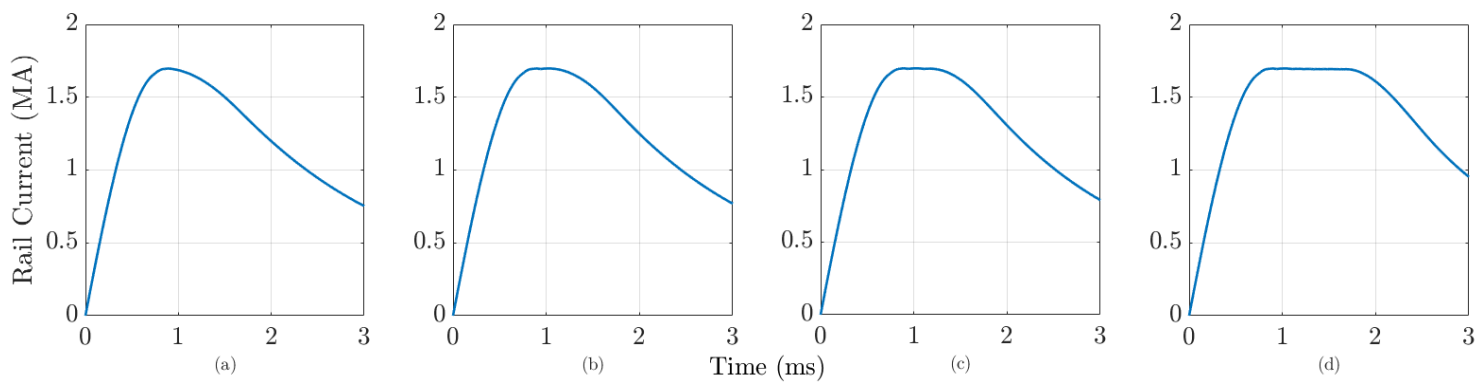

Fig. 7. Intermediate results of the pulse current algorithm. The algorithm search for trigger time which is defined as moment that rail current decreased from $\mathrm{I}_{\mathrm{ref}}$. Then, it restart the simulation with a new triggering time, and search for next. While iterations continue, the rail current becomes pulse shape current with increasing width.

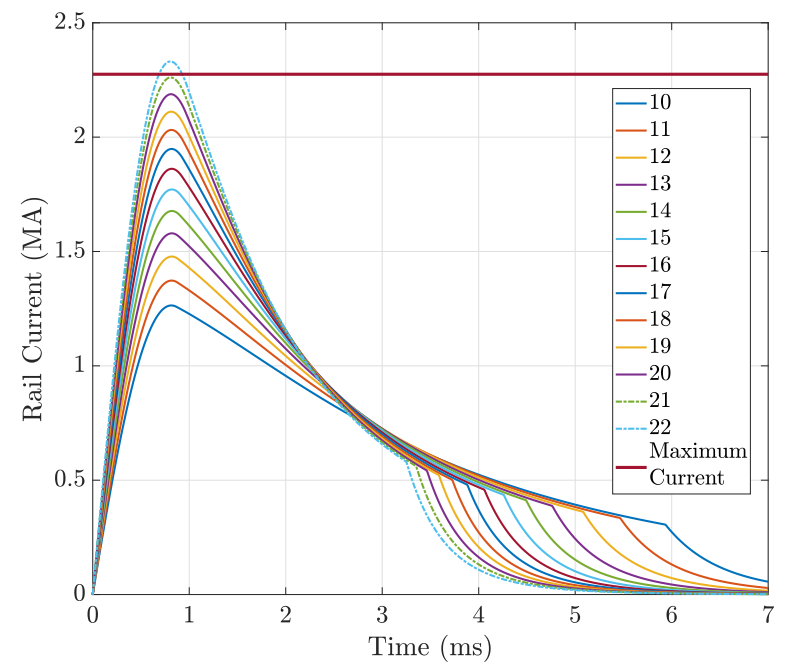

Fig. 8. Peak current vs. number of modules triggered at $\mathrm{t}=0 \mathrm{~ms}$. The dashed current lines exceeds the maximum current density in Table 1

effect of these parameters will also be discussed in the next sections. Exit velocity vs. amplitude of pulse current, $\mathrm{I}_{\text {ref }}$, is given in Fig. 9. It is clear that exit velocity is a one-toone function of $\mathrm{I}_{\text {ref }}$. Moreover, the error function, which is defined as $I_{\text {ref }}-I_{\text {ref }}^{*}$, is a uni-modal function with the given boundaries. Therefore, a line search algorithm can be used for finding proper $\mathrm{I}_{\text {ref }}$ value. In this study, we used golden section search algorithm for line search method [18]. Some steps of the golden search algorithm is illustrated in Fig. 11. The performance of the golden section algorithm is given in Fig. 12

After a few iterations, the relative error is reduced down to $0.1 \%$. Considering that one function evaluation, which finds a set of triggering time for a given $\mathrm{I}_{\text {ref }}$, takes 10 to 18 circuit simulations (depending on the number of design variable), the proposed algorithm requires a few tens of simulations for $1 \%$ relative error and one or two hundred simulations for $0.1 \%$ relative error. However, it should be noted that the performance parameter of the algorithm is relative error. Thus, the accuracy of the speed control is still heavily depends on the 1-D simulation accuracy. The scope of the paper includes a triggering strategy algorithm and exclude the pure performance of the 1-D model. However, enhancements can be made with 1-D model and the proposed triggering algorithm can be applied directly.

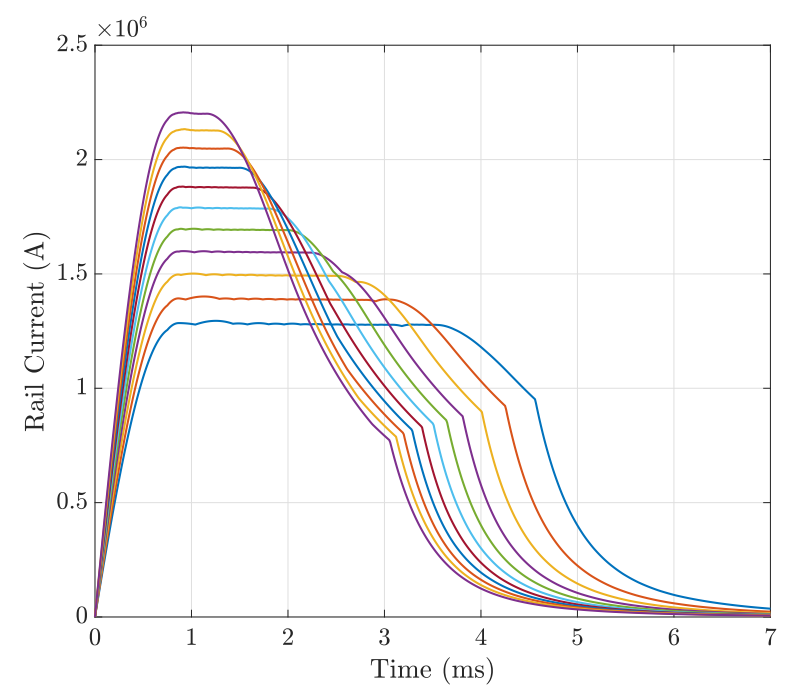

Fig. 9. The results pulse current algorithm respect to different $\mathrm{I}_{\mathrm{ref}}$. $\mathrm{N}$ denoted as module number is taken 32 . The capacitor voltage of the module are identical at $6500 \mathrm{~V}$.

\section{REsults}

Two evolutionary algorithms are implemented to solve TTOP. These algorithms create not only benchmarks to the MFTTA but also some understandings about the effects of the constraints. The parameters we used in RCGA given as in Table 2. The parameters of PSO are given Table 3. The hyper-parameter optimization for these algorithms is skipped considering the scope of this study.

A GA is a meta-heuristic optimization algorithm that is inspired by the theory of natural evolution. The algorithm shows the process of natural selection where the fittest individuals are selected for the next generation. Elitism in the GA implies the best solution obtained for the current generation and have a pass to the next generation. Notably, it means keeping the best individual found intact for the next generation. Since it has a positive impact on the convergence of the algorithm, it is also 


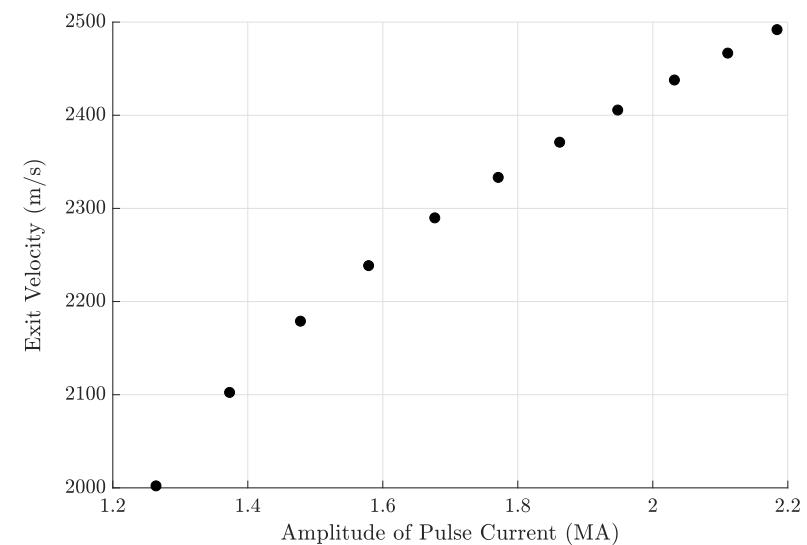

Fig. 10. Exit velocity vs amplitude of pulse current graph at $V_{c}=6500 \mathrm{~V}$. This graph indicates that there exist a unique pulse shape current for all exit velocities.

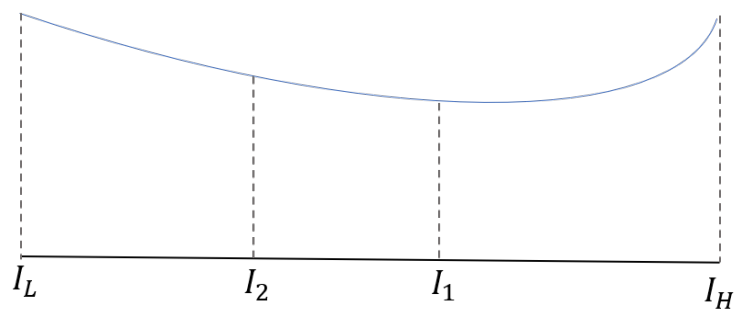

(a) Initialization with the intermediate points.

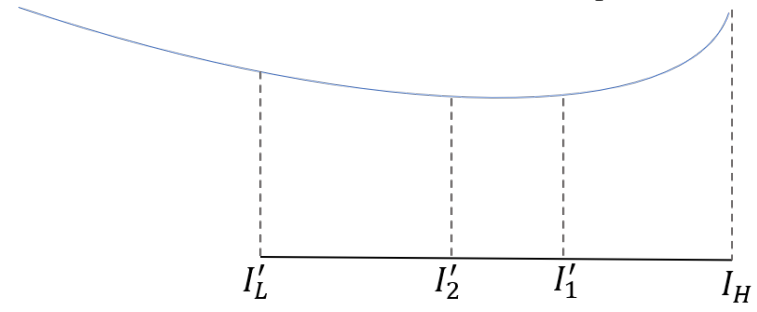

(b) Narrowing the search distance when $\left(\mathrm{I}_{1}<\mathrm{I}_{2}\right)$.

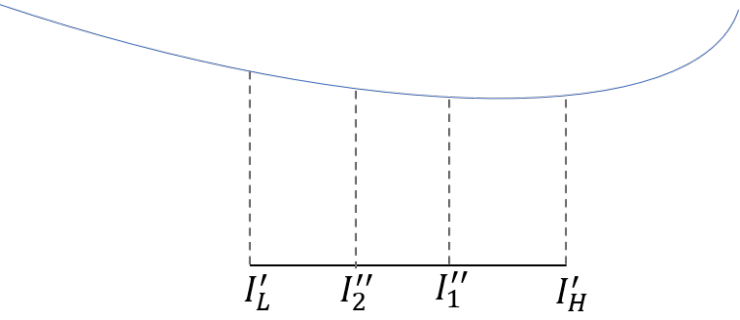

(c) Narrowing the search distance when $\left(\mathrm{I}_{2}<\mathrm{I}_{1}\right)$

Fig. 11. Same steps of the golden search algorithm.

used in this study. The tournament selection parameter is the number of individuals that sorted as a group. These groups are used crossovers, which ensure the quality of the matches.

PSO is another "nature-inspired" meta-heuristic optimization algorithm like GAs. The communication between crowds of animals, such as birds and fish, such as finding a food source and avoiding predators, increases their speed of finding the optimal solution. In this application, "birds" are the triggering times and "the search for a food source" is an analogy for obtaining the $\mathrm{v}_{\max }$.
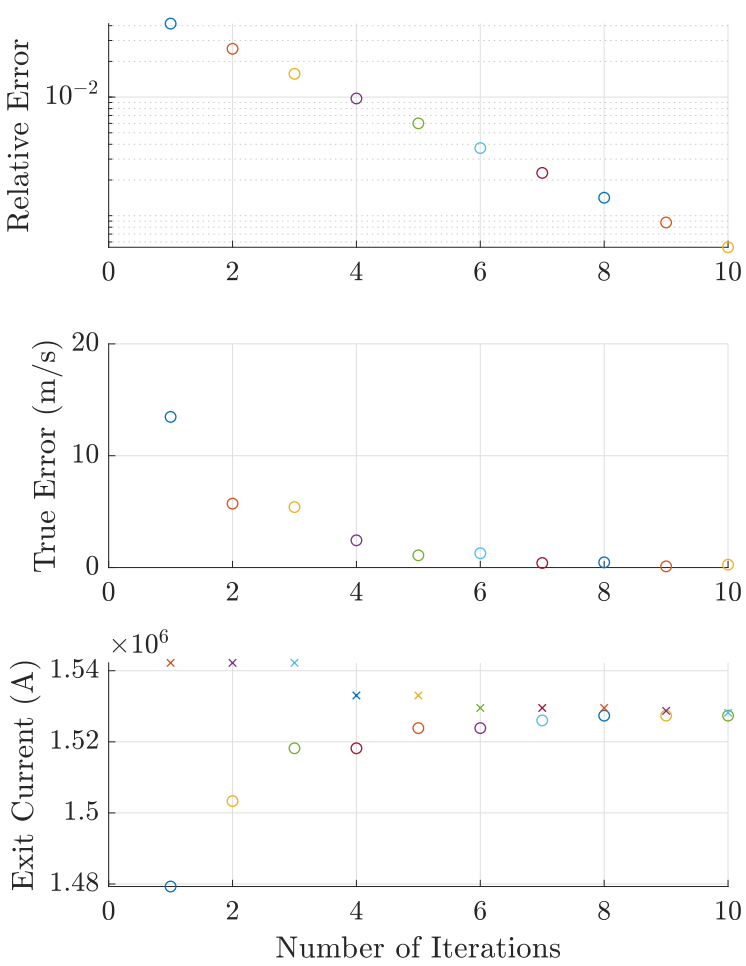

Fig. 12. The performance of golden section line search algorithm. Noted that the golden section line search algorithm uses only one function evaluation at all iterations except the initial one. Considering that one function evaluation takes 10 to 18 circuit simulations, the proposed algorithm requires a few tens of iterations for $1 \%$ relative error and one or two hundred iterations for $0.1 \%$ relative error.

TABLE III

THE PARAMETERS OF RCGA

$\begin{array}{ll}\text { Population Size } & 50 \\ \text { Number of Generation } & 100 \\ \text { The number of design parameters } & 16 \\ \text { Elite Size } & 5 \\ \text { Tournament Selection } & 10 \\ \text { Croosover Rate } & 0.8 \\ \text { Mutation Rate } & 0.2\end{array}$

TABLE IV

THE PARAMETERS OF PSO

$\begin{array}{ll}\text { Population Size } & 50 \\ \text { Number of Generation } & 100 \\ \text { The number of design parameters } & 16 \\ \text { Maximum velocity } & 0.1 \mathrm{~ms} \\ \text { Minimum velocity } & -0.1 \mathrm{~ms} \\ \text { Inertia } & 1 \\ \text { Damping Inertial Term } & 0.99 \\ \text { Social Acceleration Term } & 1.4962 \\ \text { Personal Acceleration Term } & 1.4962\end{array}$

Two different optimization studies are conducted with RCGA. These studies differ from their constraints. The $I_{\max }$ constraint is relaxed in one of the studies to show the effect. The convergence graphs are shown in Fig. 13 and 14. The objective of these studies is maximizing $\mathrm{v}_{\max }$. The best individuals of the selected iterations are illustrated in Fig. 15 


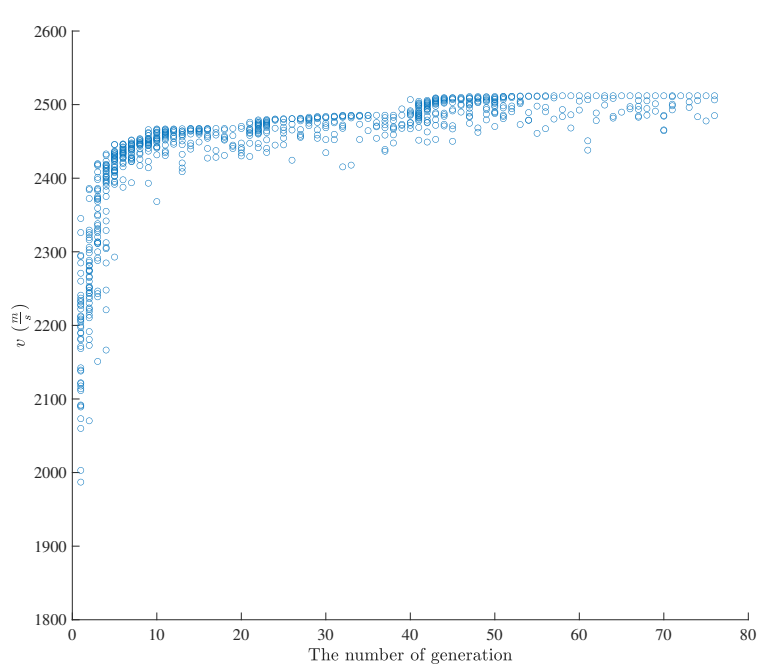

Fig. 13. Individuals of each generation and their cost values with RCGA with constraints. The population size looks like decrease after generations due to maximum current constraint.

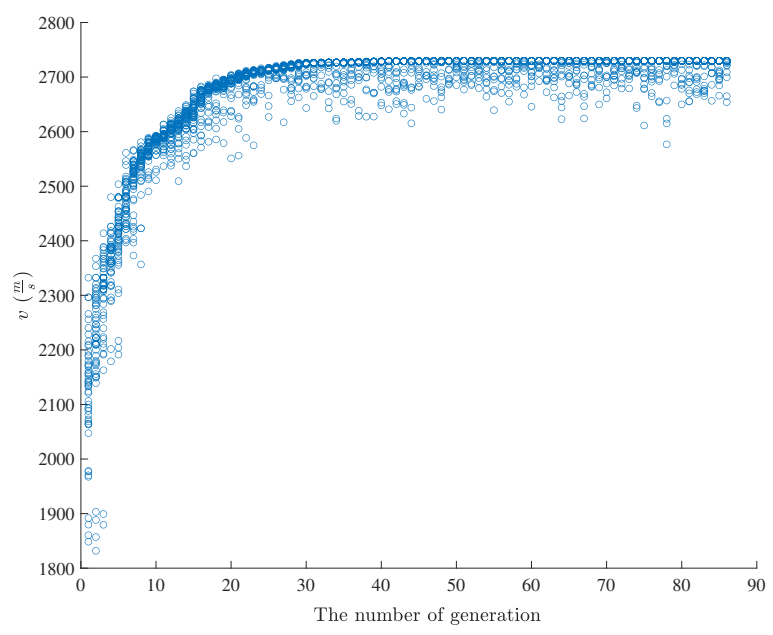

Fig. 14. Individuals of each generation and their cost values with RCGA. No constraint applied. The purpose of this study is understanding of behaviour of system with respect to triggering times. After various iterations the maximum $\mathrm{v}_{\text {exit }}$ is $2723 \mathrm{~m} / \mathrm{s}$ which corresponding to all triggering times are $0 \mathrm{~s}$. However this result violate the maximum rail current constraint.

and $16 . \mathrm{I}_{\text {rail }}$ and the velocity curves are used to visualization for triggering times. When the $\mathrm{I}_{\max }$ constraint is relaxed, the triggering time converges to all zero vector, as in Fig. 15. However, when violation of $I_{\max }$ is penalized the $I_{\text {rail }}$ is nothing but the pulse current that have $\mathrm{I}_{\max }$ length. This can be understand from Fig. 14.

The result of the PSO is demonstrated in Fig. 17. Each circle represents an individual/particle, and each color represent a generation. The movement of the particle is shown using an arrow. $\mathrm{I}_{\max }$ constraint is applied. Therefore, the comparison between and RCGA and PSO in terms of convergence should be made between Fig. 13 and 17. Although both algorithms converge the same optimum solution, RCGA reach the opti-

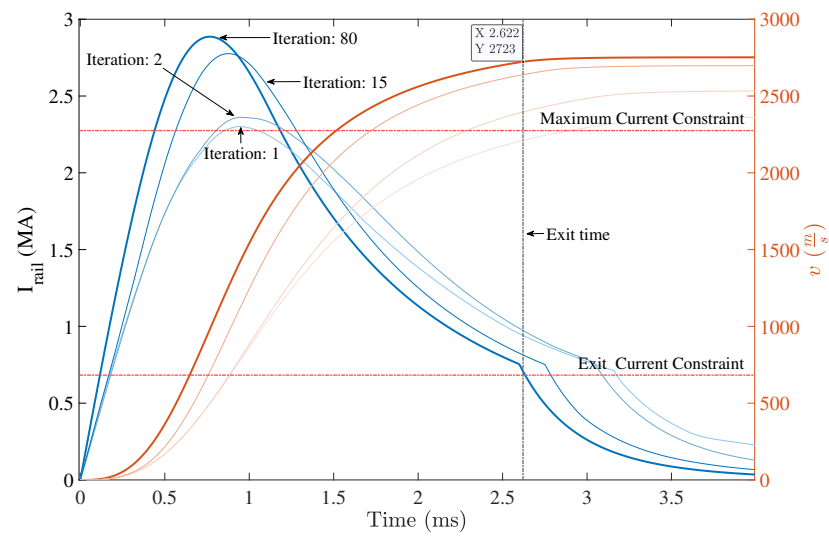

Fig. 15. Initial intermediate and final steps of RCGA without constraint. It showed that the firing sequence converged to zero vector (indicating that all PPS modules triggered initial time step). However, this condition violate the maximum rail current constraint

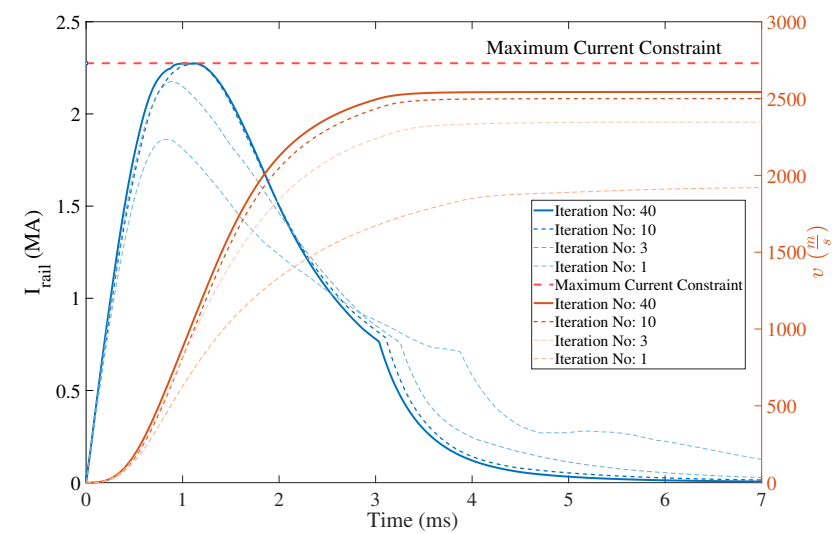

Fig. 16. Initial intermediate and final steps of RCGA with constraint. The study showed that rail current becomes pulse current that have magnitude $\mathrm{I}_{\max }$ to have maximum $v_{\text {exit }}$ and maximum efficiency $\eta$.

mum solution at 46th iteration whereas PSO reach 11th. Thus, PSO outperformed RCGA in a TTOP. The comparison of the three algorithms in terms of computational load is represented in Table 5.

TABLE V

The Performance Comparison of the Methods

\begin{tabular}{llll} 
& GA & PSO & MFTTA \\
\hline Objective: $v_{\text {desired }}$ & 2500 & 950 & 160 \\
Objective: $v_{\max }$ & 2300 & 550 & $18^{2}$ \\
\hline
\end{tabular}

${ }^{1}$ Each number represent the number of simulations/function evaluations for the given method.

${ }^{2}$ MFTTA use the information that for maximizing $v_{\max }$, the $\mathrm{I}_{\text {rail }}$ should be pulse shaped current with the magnitude $I_{\max }$.

The results showed that MFTTA outperformed GA and PSO in terms of computational load. The reason is that MFTTA has the ability to transform multiple input features (triggering times) to one input feature, $\mathrm{I}_{\text {ref }}$. Since the search space dimension is reduced to one, and the error function is uni-modal, a simple line search algorithm can minimize the 


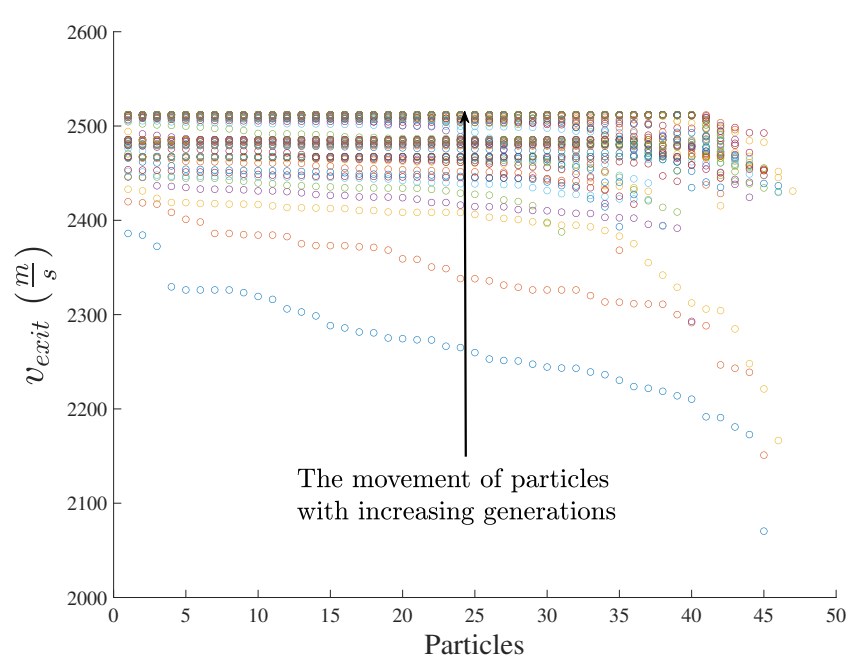

Fig. 17. The result of Particle Swarm Optimization. The result are consistent with RCGA

error with a few iterations. In Fig. 18, different MFTTA results are illustrated to understand the behavior of various triggering strategies better. For a specified $v_{\text {exit }}$, there are multiple $I_{\text {rail }}$ guarantees the $\mathrm{v}_{\text {exit }}$ and each of them has different PPS voltage denoted as $\mathrm{V}_{\mathrm{c}}$. This situation is illustrated in Fig. 19. Six different $\mathrm{I}_{\text {ref }}$ and their set of triggering times that guarantee $2153 \mathrm{~m} / \mathrm{s}$ muzzle speed are obtained. The most efficient one is the one that has the lowest $\mathrm{V}_{\mathrm{c}}$. Consequently, this solution also has the lowest $\mathrm{I}_{\text {exit }}$. Therefore, there is a trade-off between efficiency and the risk of transition.

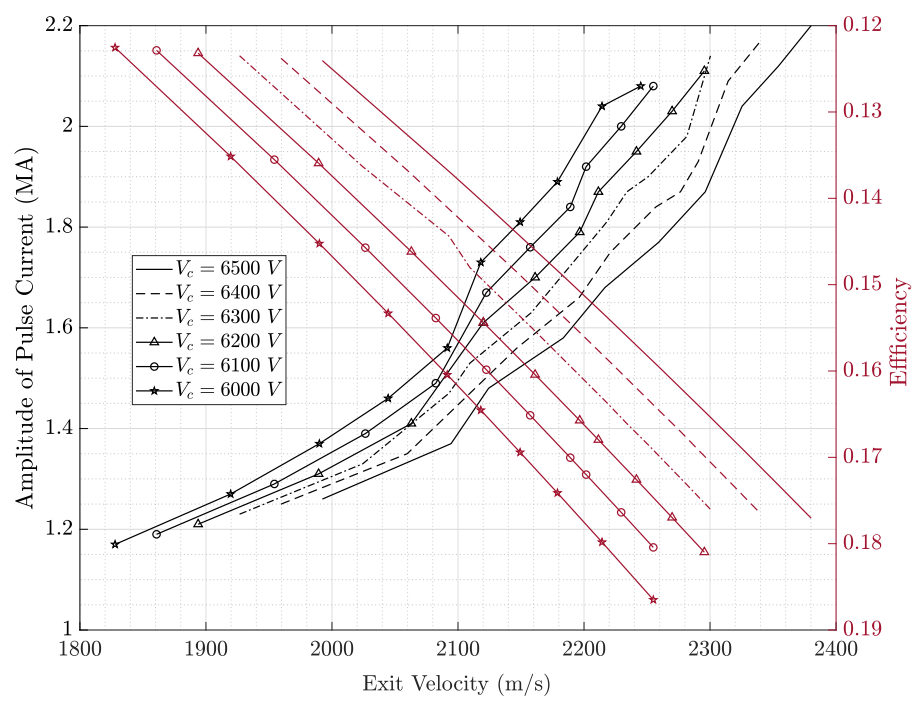

Fig. 18. Variation of peak current and projectile to input power efficiency vs. projectile speed for different capacitor charge voltages.

\section{Discussion}

This study is conducted with the motivation of searching a triggering strategy under different EML objectives. Although

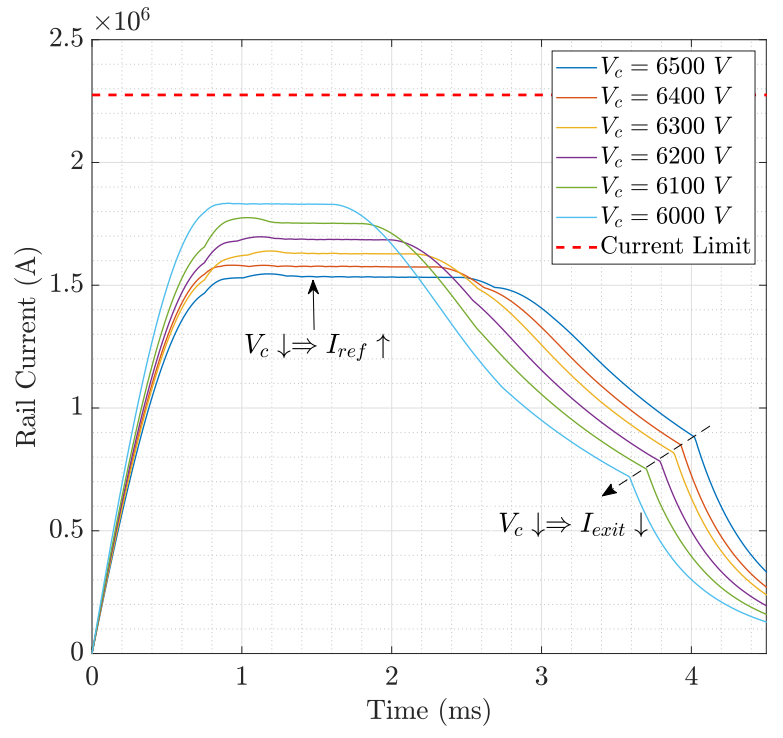

Fig. 19. Various pulse currents with different capacitor voltages which satisfy desired exit velocity $\nu_{\text {exit }}=2153 \mathrm{~m} / \mathrm{s}$. Decrease in capacitor voltage for fixed exit velocity leads to increase at pulse current magnitude $I_{\text {ref }}$ and decrease in exit current $\mathrm{I}_{\text {exit }}$. Efficiency increases when the capacitor voltage decreased however increase in $\mathrm{I}_{\mathrm{ref}}$ and decrease in $\mathrm{I}_{\text {exit }}$ increase the risk of the transition. [15]

the simulation model's accuracy is sought, the fundamental novelty of the study is the methodology of obtaining triggering times. The methodology can be applied to different 1-D simulation models as well as 3-D FEM simulations.

Hyper-parameter optimization of the benchmark methods (GA and PSO) is skipped. The main goal of adding these methods to the study is to give a figure of merit the advantages of the iterative methods in TTOP. Moreover, the convergence of these methods gives insights about the behavior of triggering times when the maximum efficiency is targeted.

Although the down-slope transition is linked with $I_{\text {exit }}$ between $80-90 \%$ of $\mathrm{I}_{\text {ref }}$ in the literature, there are some reported experiments with lower $\mathrm{I}_{\text {exit }}$ percentage no-transition [17]. Thus, in this study the constraint is settled a lower value $40 \%$. However, this parameter can be re-adjusted considering the new $\mathrm{I}_{\text {exit }}$ constraint.

\section{CONCLUSION}

In this study TTOP solved by various algorithms such as RCGA, PSO and the proposed iterative method, MFTTA. In this paper not only the comparison of iterative and evolutionary method but also the novelty of 1-D simulation model introduced. The optimization results are used to show trade offs of different triggering strategies. These remarks are listed as following;

1) Without constraints, the triggering times at TTOP converge to zero vector which indicates all PPS modules triggered at initial time step to have maximum $\mathrm{v}_{\text {exit }}$. However, resulting rail current exceeds the maximum rail current limit which has harmful effect on the rails. 
2) Considering the current constraints, the rail current converge to pulse shaped current which have magnitude $I_{\max }$ when the objective is $v_{\max }$.

3) Evolutionary based algorithms are slower than iterative based algorithms for triggering time calculation of EML's. With increasing module number of PPS the performance of evolutionary algorithms become even worse due to necessity of increasing the number of individuals and generations. Iterative based computation is more robust to the increase in the module number.

4) The uniqueness of $I_{\text {ref }}$ with the given exit velocity is valid if and only if the capacitor voltage and launch package mass are fixed. Therefore, there must an optimum $I_{\text {ref }}$ that satisfies the desired launch package exit velocity and increases the overall system efficiency and satisfy other transition constraints.

5) For the same desired exit velocity, it is possible to generate multiple current pulse wave-forms as in Fig. 19. As the capacitor voltage decreases, the launch efficiency increases, the peak current increases and the exit current decreases. Increasing the peak and decreasing exit current result in transition between armature-rail interface. Therefore, a compromise has to be made during selection of launch triggering sequence and capacitor charge voltages.

\section{ACKNOWLEGMENT}

The authors would like to thank Mustafa Karagöz, Baran Yıldırım, and Ibrahim Güngen for their support and collaboration.

\section{REFERENCES}

[1] J. Wey, P. Lehmann, and H. Peter, "Des 3 mj-railgun experimental results at isl," IEEE Trans. Magn., vol. 31, no. 1, pp. 371-376, Jan 1995.

[2] S. Hundertmark, G. Vincent, F. Schubert, and J. Urban, "The ngl-60 railgun," IEEE Trans. Plasma Sci., vol. 47, no. 7, pp. 3327-3330, July 2019.

[3] P. Lehmann, H. Peter, and J. Wey, "First experimental results with the isl $10 \mathrm{mj}$ des railgun pegasus," IEEE Trans. Magn., vol. 37, no. 1, pp. 435-439, Jan 2001.

[4] C. Gong, X. Yu, and X. Liu, "Study on the system efficiency of the capacitive pulsed-power supply," IEEE Transactions on Plasma Science, vol. 43, no. 5, pp. 1441-1447, May 2015.

[5] A. J. Ma, B. D. Zhang, C. W. Yuan, R. Yuan, W. Xu, and P. Yan, "A method of generating timing for a given target current waveform in electromagnetic launch technology," IEEE Transactions on Plasma Science, vol. 45, no. 7, pp. 1561-1566, 2017.

[6] S. F. Glover, F. E. White, K. W. Reed, and M. J. Harden, "Genetic optimization for pulsed-power system configuration," IEEE Transactions on Plasma Science, vol. 37, no. 2, pp. 339-346, 2009.

[7] X. Chang, X. Yu, X. Liu, and Z. Li, "Armature velocity control strategy and system efficiency optimization of railguns," IEEE Transactions on Plasma Science, vol. 46, no. 10, pp. 3634-3639, 2018.

[8] S. Zhengjun and Y. Xinjie, "Two-objective optimization design for pulsed power supply," IEEE Transactions on Magnetics, vol. 45, no. 1, pp. 525-530, 2009.

[9] X. Yu and Z. Fan, "Simulation and two-objective optimization of the electromagnetic-railgun model considering vsec resistance and contact resistance," IEEE Transactions on Plasma Science, vol. 39, no. 1, pp. 405-410, 2011.

[10] H. Zhang, G. Cheng, W. Guo, Z. Su, T. Zhang, and Y. Yang, "Calculating timing sequence of capacitor-based railgun with given muzzle velocity," IEEE Transactions on Plasma Science, vol. 43, no. 9, pp. 3298-3303, 2015.
[11] H. Zhang, G. Cheng, W. Guo, Z. Su, and T. Zhang, "A lumped parameter model and its code for capacitor-based railgun with arbitrary number of pfus," IEEE Transactions on Plasma Science, vol. 42, no. 8, pp. 20982103, 2014.

[12] T. Chao, Y. Yan, P. Ma, M. Yang, and Y. W. Hu, "Optimization of electromagnetic railgun based on orthogonal design method and harmony search algorithm," IEEE Trans. Plasma Sci., vol. 43, no. 5, pp. 1546-1554, May 2015.

[13] J. P. Barber, D. P. Bauer, K. Jamison, J. V. Parker, F. Stefani, and A. Zielinski, "A survey of armature transition mechanisms," IEEE Transactions on Magnetics, vol. 39, no. 1, pp. 47-51, 2003.

[14] Z. Wang, L. Chen, S. Xia, and C. Li, "Experiments and analysis of downslope low-voltage transition in c-type solid armature rail gun," IEEE Transactions on Plasma Science, vol. 48, no. 7, pp. 2601-2607, 2020.

[15] S. Satapathy and H. Vanicek, "Down-slope contact transition in railguns," IEEE Transactions on Magnetics, vol. 43, no. 1, pp. 402-407, 2007.

[16] D. Ceylan, M. Karagoz, Y. Cevik, B. Yildirim, H. Polat, and O. Keysan, "Simulations and Experiments of EMFY-1 Electromagnetic Launcher," IEEE Trans. Plasma Sci., vol. 47, no. 7, pp. 3336-3343, 2019.

[17] N. Tosun, H. Polat, D. Ceylan, M. Karagoz, B. Yıldırım, Güngen, and O. Keysan, "A hybrid simulation model for electromagnetic launchers including the transient inductance and electromotive force," IEEE Transactions on Plasma Science, vol. 48, no. 9, pp. 3220-3228, 2020.

[18] E. K. P. Chong and S. H. Zak, An introduction to optimization, 2nd ed., ser. Wiley-Interscience series in discrete mathematics and optimization. New York: Wiley, 2001.

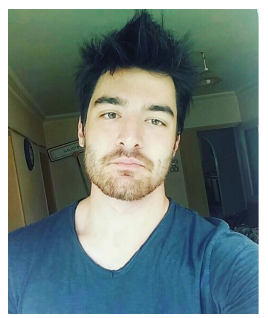

Nail Tosun received the B.Sc. degree from the Department of Electrical and Electronics Engineering, Middle East Technical University (METU), Ankara, Turkey, in 2019, where he is currently pursuing the M.Sc. degree. His current research interests include electromagnetic FEM analysis, optimization of electrical machines and power electronics.

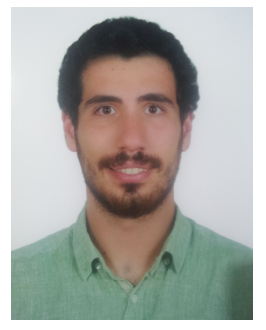

Doğa Ceylan received the B.Sc. and M.Sc. degrees from the Department of Electrical and Electronics Engineering, Middle East Technical University (METU), Ankara, Turkey, in 2016 and 2018, respectively. He is currently working toward the Ph.D. degree with the Electromechanics and Power Electronics Group at the Eindhoven University of Technology, the Netherlands. His current research interest focuses on design and optimization of electrical machines, electric vehicles, and electromagnetic launchers.

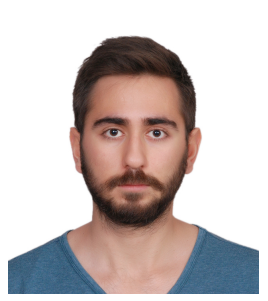

Hakan Polat received the B.Sc. degree from the Department of Electrical and Electronics Engineering, Middle East Technical University (METU), Ankara, Turkey, in 2018, where he is currently pursuing the M.Sc. degree. His current research interests include, electromagnetic launchers, pulsed-power sources, renewable energy and wireless power transfer. 


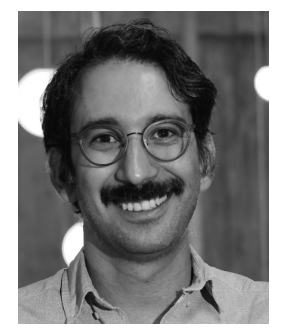

Ozan Keysan received the master's degree from Middle East Technical University (METU), Ankara,

Turkey, in 2008, and the Ph.D. degree from the University of Edinburgh, Edinburgh, Scotland, in

2014. He is currently an Assistant Professor with the

Electrical and Electronics Engineering Department,
METU. His current research interests include renewable energy, design and optimization of electrical machines, smart grids, superconducting machines, and permanent-magnet machines. 